\title{
Optimization of a Six-Strand Continuous Casting Tundish: Industrial Measurements and Numerical Investigation of the Tundish Modifications
}

\author{
TOMASZ MERDER and MAREK WARZECHA
}

The main differences in the transient zone extent between the individual strands for the former industrial six-strand tundish configuration is the basis for undertaking this study. The aim this study was to improve the casting conditions by proposing the optimal equipment of the tundish working space. For economic reasons, only the variants with different baffles configurations were considered. It was also dictated by the simplicity of construction and the possibility of its implementation by the base operating steel mill. In the current study, industrial plant measurements and mathematical modeling were used. Industrial experimental data were used to diagnose the current state of the industrial tundish and then validate the numerical simulations. After this, the influence of different baffle configurations installed in the tundish on the steel flow characteristic was modeled mathematically. Residence time distribution (RTD) curves are plotted, and individual flow shares for the investigated tundish were estimated based on the curves. Finally, the industrial plant was rebuilt according to the numerical results and additional plant measurements were performed. A result of the appearance of the baffles in the tundish working space was the reduction of the transient zone extent. The results indicate the increasing share of the dispersed plug flow and a decreasing share of the dead volume flow, with a practically unchanging share of well-mixed volume flow in the modified tundish.

DOI: $10.1007 / \mathrm{s} 11663-012-9662-2$

(C) The Author(s) 2012. This article is published with open access at Springerlink.com

\section{INTRODUCTION}

MODERN continuous steel casting (CSC) plants, together with the steelmaking furnace and secondary metallurgy units, provide a compact and efficient manufacturing process. Because of the growing demands for quality in metallurgical production, new engineering solutions are being developed to eliminate the current drawbacks of the continuous casting technology. The current state of this technology development allows the casting of liquid steel semifinished products with a shape and cross-sectional dimensions that is close to those of the finished products.

The role of the tundish as an active metallurgical reactor has come to the forefront in this study. It is necessary to understand and describe the flow, transfer, and thermal phenomena that occur during the casting of steel.

These studies involve numerous rectangular tundishes provided with two nozzles ${ }^{[1]}$ being in use (from singleand multiple-strand through-type ${ }^{[2,3]}$ or "delta"-type units $^{[4,5]}$ to untypical "V"-type, ${ }^{[6]}$ "H"-type, ${ }^{[7]}$ and "L"type units $\left.{ }^{[8,9]}\right)$. Among the research results reported in

TOMASZ MERDER, Research Associate, is with the Department of Metallurgy, Silesian University of Technology, 40-019 Katowice, Poland. MAREK WARZECHA, Senior Research Associate, is with the Department of Metals Extraction and Recirculation, Czestochowa University of Technology, 42-200 Czestochowa, Poland. Contact e-mail: warzecha@wip.pcz.pl

Manuscript submitted December 28, 2010.

Article published online April 12, 2012. the literature, multistrand tundishes seldom occur. Most of the reported studies involve the flow of steel and separation of inclusions in single- or two-strand tundishes. However, the conditions of both the flow and nonmetallic inclusion separation are much more complex, especially taking into account the differences in the quality of the concasts in the individual strands of a CSC machine. Studies on multistrand tundishes are additionally valuable as such tundishes predominate in Poland's metallurgical industry because of the production profile. ${ }^{[10-12]}$ Tundishes are equipped with various types of flow controllers, such as dams, baffles, weirs, ${ }^{[13,14]}$ turbulence inhibitors (e.g., "turbostop" plates) ${ }^{[3,15,16]}$ or gas curtains. ${ }^{[17]} \mathrm{A}$ common practice in making modifications to the internal working space of a tundish is also to combine the different flow control devices. ${ }^{[13,15,18]}$ Investigations have shown that if flow control devices are used, then the hydrodynamic conditions that occur in the tundish improve considerably; however, mounting a flow control device in an inappropriate location might impair these conditions.

Research output in this field, as can be found in literature, is vast and methodologically diverse. The main currents of the presented studies concern physi$\mathrm{cal}^{[19,20]}$ and numerical modeling of flow phenomena and refining processes. ${ }^{[4,6,16]}$ Reports concerning the experimental tests carried out on commercial plants are available. ${ }^{[10,21,22]}$ Studies that describe the efficiency of tundishes involved the use of macromixing characteristics called residence time distribution (RTD) relationships. ${ }^{[15,16,23,24]}$ The most important relationships 
include the theoretical and actual residence time of the medium in the tundish, type $\mathrm{F}$ and type $\mathrm{E}$ residence time distribution curves, and estimated volumetric fractions of zones with different flow types in the tundish, such as dispersed plug flow, well-mixed volume flow, and dead volume flow. RTD characteristics are used for comparing tundishes with different geometric shapes and different working space equipment.

Numerical and physical studies, as well as the experimental tests described in the literature, provide plenty of important information when designing and upgrading the tundishes. Particularly important is the fact that the investigation results obtained from laboratory models and commercial facilities can verify the numerical modeling. Therefore, the use of numerical studies has become common practice. Computational fluid dynamics (CFD) programs $s^{[4,6,15,17,25]}$ relying on fluid mechanics methods are employed contemporarily for such computations.

In the current work, an attempt was made to use numerical studies to unveil the nature of the hydrodynamic phenomena occurring in an existing tundish operated in Poland's metallurgical industry. This type of tundish is a multistrand tundish with a geometry adapted to the conditions of the specific CSC plant. The industrial measurements were performed to diagnose the current flow in the tundish. The problems postulated in the author's studies were solved using the numerical method based on the Navier-Stokes equations. The indicated method makes it possible to describe effectively the dynamics of the processes occurring in a single-phase and a multiphase metallurgical system, allowing for the transfer of mass, momentum, and energy. Currently, it is used widely in the comprehensive analysis of a commercial plant.

The obtained simulation results were compared with the experimental test results. This process involved comparing the RTD curves (of the F type) obtained as a result of numerical modeling and the industrial experiment. The numerical studies also show that modifications in the tundish working spaces are required. The numerical simulations made it possible to evaluate (1) the liquid steel velocity, (2) the temperature fields, and (3) the concentrations of the tracer in steel (curves F and E) for the proposed variant of tundishes during transient casting conditions (steel grade change). The obtained characteristics enabled the selection of the optimal variant of tundish equipment for the desired conditions of the plant's operation. Unlike several previous studies, the optimal tundish working space configuration has been implemented in the industrial plant, which made it possible to test the working conditions of the proposed tundish configurations in reality and to perform additional validation of the mathematical model.

\section{TUNDISH DESCRIPTION}

The subject of this study is a CSC tundish operating in a Polish steel plant. This trough-type tundish has six nozzles and a nominal capacity of 15 tons. It is used for the casting ingots intended for the production of small
Table I. Tundish Working Conditions

\begin{tabular}{lll}
\hline Parameters & \multicolumn{1}{c}{ Value } & Unit \\
\hline Nominal capacity & 15 & ton \\
Molten steel level & 550 & $\mathrm{~mm}$ \\
Shroud diameter & 50 & $\mathrm{~mm}$ \\
Nozzle diameter & 17 & $\mathrm{~mm}$ \\
Number of tundish nozzles & 6 & - \\
Casting speed & 1.7 & $\mathrm{~m} / \mathrm{min}$ \\
Slab section & $160 \times 160$ & $\mathrm{~mm}$ \\
Inlet temperature & $1823(1550)$ & $\mathrm{K}\left({ }^{\circ} \mathrm{C}\right)$ \\
\hline
\end{tabular}

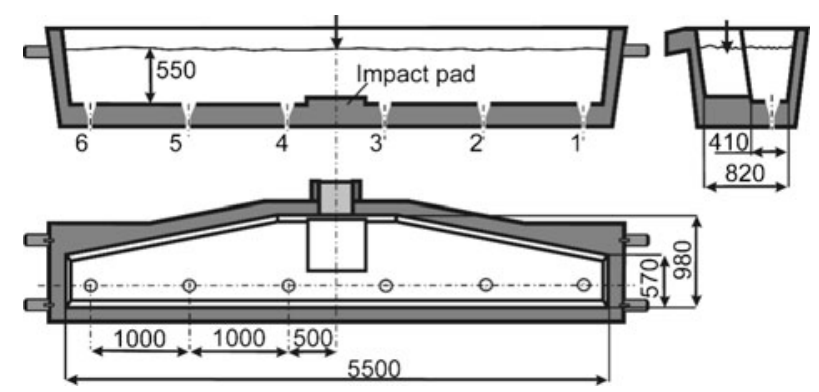

Fig. 1-Tundish configurations before the optimization (industrial tundish).

cross-section rolled products. It is symmetrical with respect to its central cross section. The basic refractory lining is made up of andalusite tiles, and the working layer is made up of a high-magnesite gunite mix. The tundish is equipped with an impact pad. The tundish used for sequence casting (more than 10 heats). The technological conditions of tundish operation, as used in numerical simulations, are given in Table I. Figure 1 shows the scheme of analyzed tundish with its major dimensions.

Excessive differences in the transient zone extent between individual strands of the existing tundish provided grounds for undertaking studies, for which the basic aim is to improve those conditions by proposing optimal equipment of the working space. The transient zone extent was determined based on the difference in the times necessary for reaching concentrations at a level of $20 \mathrm{pct}$ and 80 pct of the expected concentration for a given steel grade. Needless to say, the lesser transient zone extent is when the conditions are better in the tundish for sequence casting of different steel grades, as there is a smaller quantity of steel that does not or might not meet the requirements specified by the standard for a particular steel grade. The previously mentioned characteristic is used commonly for the assessment and comparison of the working spaces of different tundishes. ${ }^{[23]}$

First, an attempt was made to diagnose the state of the existing tundish operation. Then, tundish equipment variants, as shown in Figure 2, were proposed. In reality, they do not exist and are only a proposal for plant interior modifications and are the subjects of numerical computations. Three variants of tundishes equipped with various flow control devices are proposed, including baffles and notched baffles. 
The tundish working space after modification contains two simple baffles or notched baffles mounted in the liquid steel pouring zone. This modification has created a space limited by the baffles, performing the role of a "container" - an actual turbulence controller whose task will be to reorient the flow of the liquid steel stream. This state should bring about the effect of separating the gate zone from the nozzle zone, which as a consequence should decrease the transient zone, increase the share of dispersed plug flow, and improve the liquid steel refining conditions.

\section{INDUSTRIAL INVESTIGATIONS}

The author's experimental test results are partially reported elsewhere. ${ }^{[1,26]}$ The tests were carried out in industrial conditions in a continuous steel casting stand in a Polish steel plant. The reactor under test was a tundish with an impact pad as shown in Figure 1. An abrupt chemical disturbance method was employed in the experiment. The state of the metal bath in the tundish was examined up to the moment, when two heats of the same steel grade, but differing in tracer

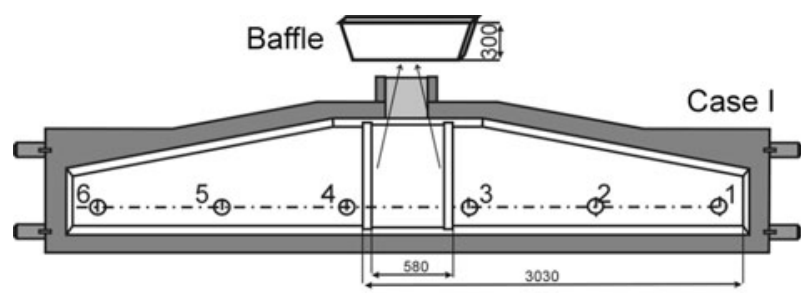

(a)

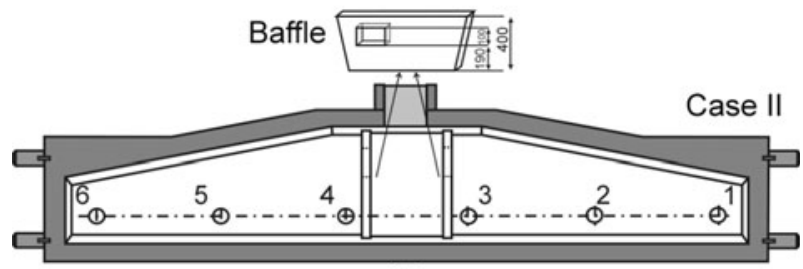

(b)

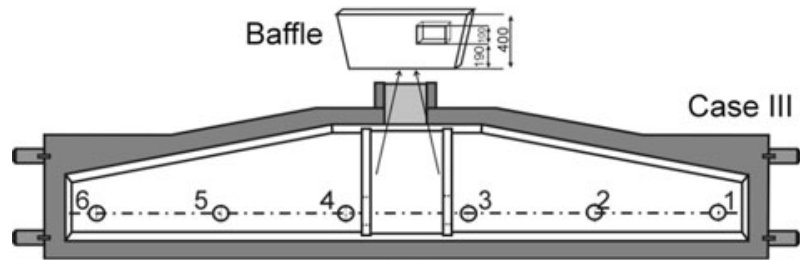

(c)

Fig. 2-Schematics of the proposed outfit of the tundish working space: $(a)$ baffles; $(b)$ notched baffles, Variant 1 ; and $(c)$ notched baffles, Variant 2. concentration, followed after themselves. The first heat (A) contained as little tracer element as possible, whereas the other heat (B) contained much more than the former. The tracer element content was increased by introducing, already in the ladle furnace, considerable amounts of pure copper in the form of mold plates. The choice of the tracer element was not accidental. It was selected because $\mathrm{Cu}$ is an element with negligible chemical affinity with respect to the remaining steel components. The steel grade selected for the experiment was steel BSt500S, for which large variations in copper concentration are permissible. The contents of major components in the tested steel grade are given in Table II.

The tests included the analysis of chemical composition of samples taken from the CSC machine molds. Sampling was done using vacuum immersion samplers. The copper concentration was measured manually at different locations by putting testers in previously marked places. The sampling method was performed by liquid steel ingestion through a quartz tube into a metal mold mounted in the sampler. For each measurement, one probe has been taken from each measuring location. Figure 3 illustrates the sampling idea.

Three experimental determinations were made during the tests. Table III presents the results of these determinations. Samples were taken from molds 1, 2, and 3 for measurement 1, and from molds 4, 5, and 6 for measurements 2 and 3 . The samples were taken at equal time intervals. Figure 4 shows the system of numbering

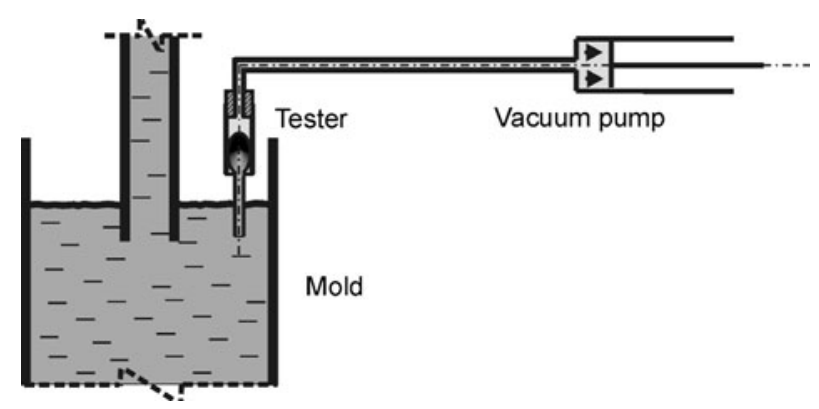

Fig. 3-Steel sampling in the molds.

Table III. Copper Concentrations Assayed in Steel ${ }^{[21]}$

\begin{tabular}{lcc}
\hline & \multicolumn{2}{c}{ Concentration $\mathrm{Cu}\left(\mathrm{Pct}_{\text {mas }}\right)$} \\
\cline { 2 - 3 } Measurement & Melt A & Melt B \\
\hline 1 & 0.35 & 0.40 \\
2 & 0.248 & 0.418 \\
3 & 0.234 & 0.418 \\
\hline
\end{tabular}

Table II. Chemical Composition of the Steel Grade (BSt500S)

\begin{tabular}{lcccccccc}
\hline & $\mathrm{C}$ & $\mathrm{Mn}$ & $\mathrm{Si}$ & $\mathrm{P}$ & $\mathrm{S}$ & $\mathrm{Cr}$ & $\mathrm{Ni}$ & $\mathrm{Cu}$ \\
\hline Minimum & 0.14 & 0.60 & 0.10 & $\overline{-}$ & $\overline{-}$ & - & - & - \\
Maximum & 0.18 & 0.70 & 0.15 & 0.04 & 0.04 & 0.3 & 0.3 & 0.4 \\
\hline
\end{tabular}




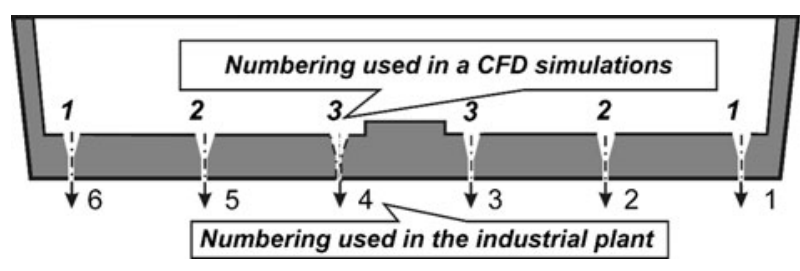

Fig. 4-Numbering of CSC machine molds and tundish nozzles.

CSC machine molds in steelwork and tundish nozzles (CFD modeling).

The analysis of chemical composition of steel samples was conducted using an emission spectrometer. The assay was based on the excitation of the test sample emission spectrum in an argon atmosphere with a lowvoltage spark. As a result, the average value from three sparks was obtained.

The copper concentrations assayed in the steel samples taken from the molds enable their variations with the time of casting, which will provide information about the response of the casting system to the introduced disturbance. Thus, the plotted RTD response curve provides a basis for determining the extent of the transient zone.

\section{NUMERICAL MODELING}

The flow field in the tundish was calculated by solving the mass, momentum, and energy conservation equations, which can be found in References 25, 27, and 28 . They are solved together with the turbulence kinetic energy $(k)$ and dissipation rate of the turbulence kinetic energy $(\varepsilon)$ equations. ${ }^{[29]}$

The residence time distribution is a statistical representation of the time spent by an arbitrary volume of the fluid in the tundish. It is obtained by changing the conditions at the inlet and measuring the system response at the outlet as a function of time. When the dimensionless concentration at the outlet is registered against dimensionless time, it creates the RTD curve. For generating the curve, a scalar model is used. It solves the following equation for the time evolution of the species mass fraction $\mathrm{C}$, giving the steady flow velocities calculated previously from the turbulence model:

$$
\frac{\partial\left(\rho_{c} C\right)}{\partial t}+\frac{\partial\left(\rho_{c} u_{i} C\right)}{\partial x_{i}}=\frac{\partial}{\partial x_{i}}\left(\rho_{c} D_{\mathrm{eff}} \frac{\partial C}{\partial x_{i}}\right)
$$

The effective diffusion coefficient $\left(D_{\text {eff }}\right)$ is the sum of the molecular diffusion coefficient and the turbulent diffusion coefficient

$$
D_{\text {eff }}=D_{\mathrm{m}}+D_{\mathrm{t}}
$$

The turbulent diffusion coefficient is determined from the following relationship (assuming that the turbulent Schmidt number equals unity):

$$
\frac{\rho D_{\text {eff }}}{\mu_{\text {eff }}} \cong 1
$$

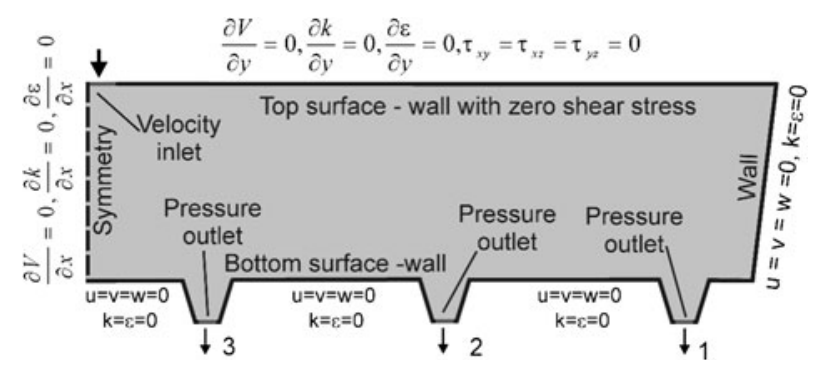

Fig. 5-Boundary conditions adapted in calculations.

To solve the differential equation system, it is necessary to assume suitable initial and boundary conditions, corresponding to the model investigation conditions. As a result of the industrial casting conditions, in the computations, the boundary condition of inlet is steel velocity equals $2.4 \mathrm{~m} / \mathrm{s}$ and 5 pct of turbulent intensity. Figure 5 shows the boundary conditions used in the computations.

The detailed boundary and operating conditions that correspond to the conditions of the industrial process can be found in Reference 26 .

The considered system is three-dimensional and symmetrical. Because of the symmetry plane, only half of the tundish was considered in the numerical computation. The computational space discretization has been made by means of the computational mesh consisting of 300,000 control volumes. The mesh is denser in the inlet and outlet regions.

For the computation of the liquid steel flow through the tundish, the boundary condition of the "no-slip" type was adapted for all walls, using the so-called "wall function." ${ }^{[30]}$ In the computations, the steel free surface was assumed as a flat surface - a wall with zero shear stresses. The SIMPLE numerical algorithm was used to solve those equations. During iteration, the convergence was assumed to reach a point where all the normalized residuals are smaller than $10^{-6}$. Computations were carried out for the transient casting conditions. The time intervals of the recorded concentration were constant in the entire testing range, being equal to $\Delta t=0.5$ seconds. The range in which continuous recording was performed was 3500 seconds. The mathematical simulations were run on a INTEL CORE i7 processor computer (Intel Corporation, Santa Clara, CA) with the CFD software Fluent (ANSYS Inc., Canonsburg, PA).

\section{RESULTS AND DISCUSSION}

\section{A. Plant Trials}

The experimental material was gathered and correlated with the data obtained from numerical simulations performed for the identical operational conditions in the tundish. Part of these original tests has already been the subject of another publication. ${ }^{[21]}$

To compare the results of the numerical simulations with the results of the industrial experiment, the tracer element concentration was converted into dimensionless characteristics using the following relationship: 


$$
C_{\mathrm{b}}=\left(C_{\mathrm{t}}-C_{\mathrm{o}}\right) /\left(C_{\infty}-C_{\mathrm{o}}\right)
$$

Figures 6 through 8 present variations of the dimensionless concentration of the tracer $(\mathrm{Cu})$ in liquid steel for the experimental tests and the numerical simulation as a function of time during steel continuous casting (during the measurement).

The discrepancies between the experimental tests and the numerical studies may originate both from the simplifications of the mathematical model and from the measuring errors. The main source of the possible errors in the industrial experiment is the liquid steel sampling technique. These include the lack of possibility of meeting the requirement to take samples from the identical location in the mold, the lack of possibility of taking the perfect measurement of sampling time (of up to 15 seconds), the measuring technique, the inhomogeneity of chemical composition, and the different quality of taken samples (from 1 to 3 sparking).

The source of error in the numerical computation, in contrast, might be the idealization of the mathematical model, e.g. the same chemical composition of the steel being cast, the same temperature, density, etc.

Nevertheless, a good qualitative agreement results between the experimental and the numerical computation in this comparison. The calculated relative error values do not exceed $10 \mathrm{pct}$, which proves that the developed numerical investigation program is formulated correctly. It would be used in subsequent numerical investigations searching for the optimal casting condition of steel in different working spaces of the tundish.

\section{B. Numerical Simulation Results}

At the subsequent stage, numerical simulations for the proposed tundish equipment modifications were carried

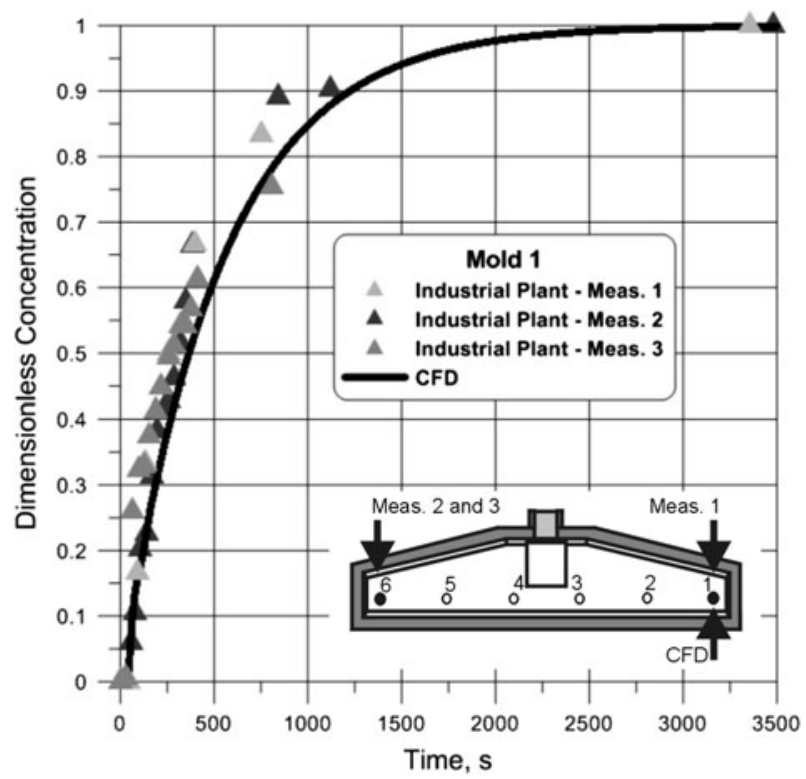

Fig. $6-\mathrm{Cu}$ concentration in steel bath measured experimentally ${ }^{[21]}$ and predicted numerically (Mold 1 ). out. From the obtained results, the characteristics were determined, as presented subsequently.

\section{Fluid flow and heat transfer}

As a result of numerical computations, velocity vector distributions, temperature fields, and tracer concentration distributions for the preset conditions were obtained. Detailed maps of the velocity vectors and temperature fields of liquid steel inside the tundish were presented in previous publications. ${ }^{[26,31]}$

Figure 9 shows the movement of liquid steel in the tundish for the analyzed test cases. The cross section passes through the tundish nozzles.

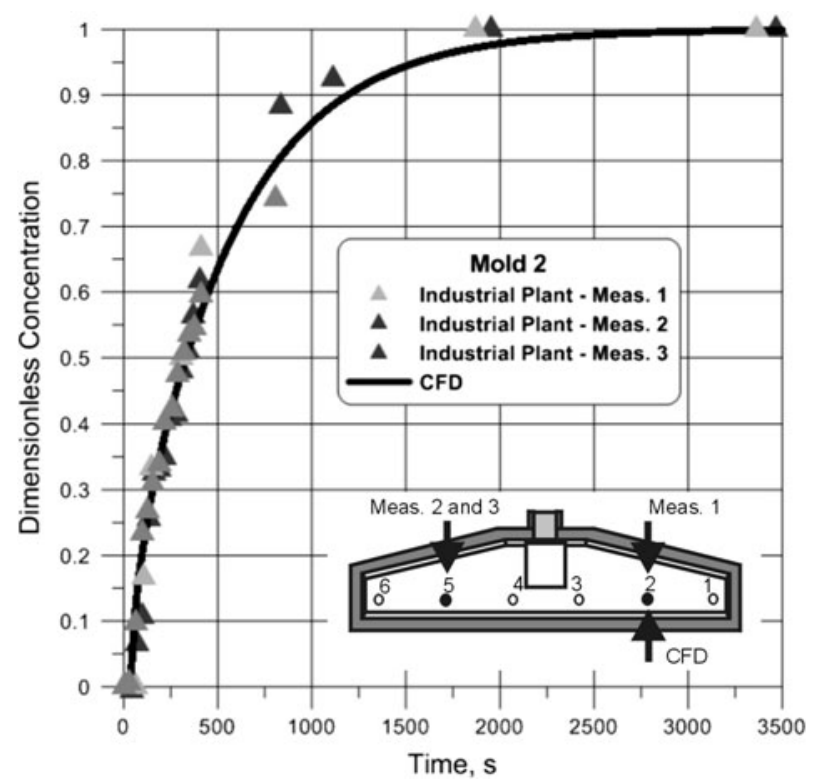

Fig. 7- $\mathrm{Cu}$ concentration in steel bath measured experimentally ${ }^{[21]}$ and predicted numerically (Mold 2).

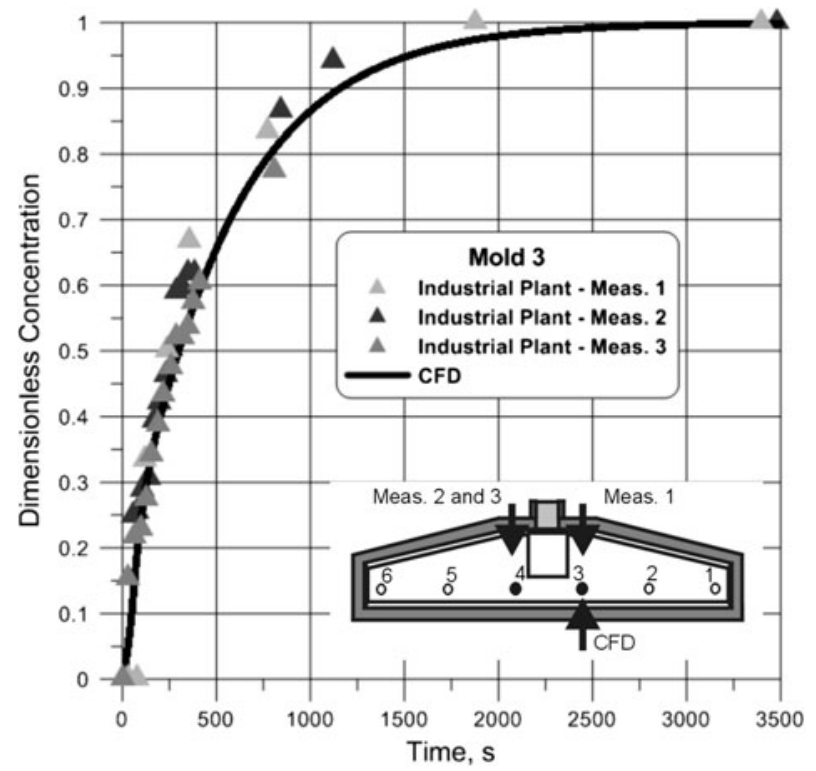

Fig. $8-\mathrm{Cu}$ concentration in steel bath measured experimentally ${ }^{[21]}$ and predicted numerically (Mold 3). 
Comparing the tundishes used currently in the industry and the proposed variants of the tundish working space modifications, several distinct changes in a flow structure and circulation of the liquid steel can be observed. Currently, working tundish is characterized by the high velocities of the fluid. In the tundish working space, not many rising streams can be found; they are essential for growing nonmetallic inclusions and removing them to the covering slag as a result of flotation.

The installation of baffles has created two working spaces. The inlet zone is separated from the nozzle zone, which as a consequence should decrease the transient zone, increase the share of dispersed plug flow and improve the liquid steel inclusion refining conditions. Steel flow structure varies significantly in each zone. The nozzle zone is characterized by areas where steel moves much slower, especially at the ends of the tundish and in the centers of vortices, resulting in a decrease of the active volume zone in the tundish and a simultaneously improvement in the conditions for removing the inclusions.

Figure 10 shows the liquid steel temperature distribution for the investigated cases. By analyzing the results of velocity vectors and temperature distributions, the common features of mass and heat flow can be observed.

Figure 10(a) presents a heterogeneous temperature distribution. The liquid steel temperature differences are not high; however, it can be noticed as different casting conditions at individual strands. The situation varies substantially with the forced movement of steel (Figures 10(b) through (d)). Thanks to baffles, whose main task is to reorient and direct the flow of the liquid steel stream, the movement of warmer fluid in the farther tundish areas is possible. Forced convection significantly changes the temperature fields in the tundish working space. In the tundishes equipped with baffles (modified configurations), a clear separation of the two zones occurs and the liquid steel temperature in the nozzle zone is more homogenous.

Installing notched baffles results in largely eliminating the heterogeneity of steel temperature distribution. The temperature distribution becomes aligned almost in the whole area outside the inlet region, and the maximum temperature difference in the whole tundish is less than $7 \mathrm{~K}$. The analysis of the steel average temperature leaving tundish through the nozzles shows that these

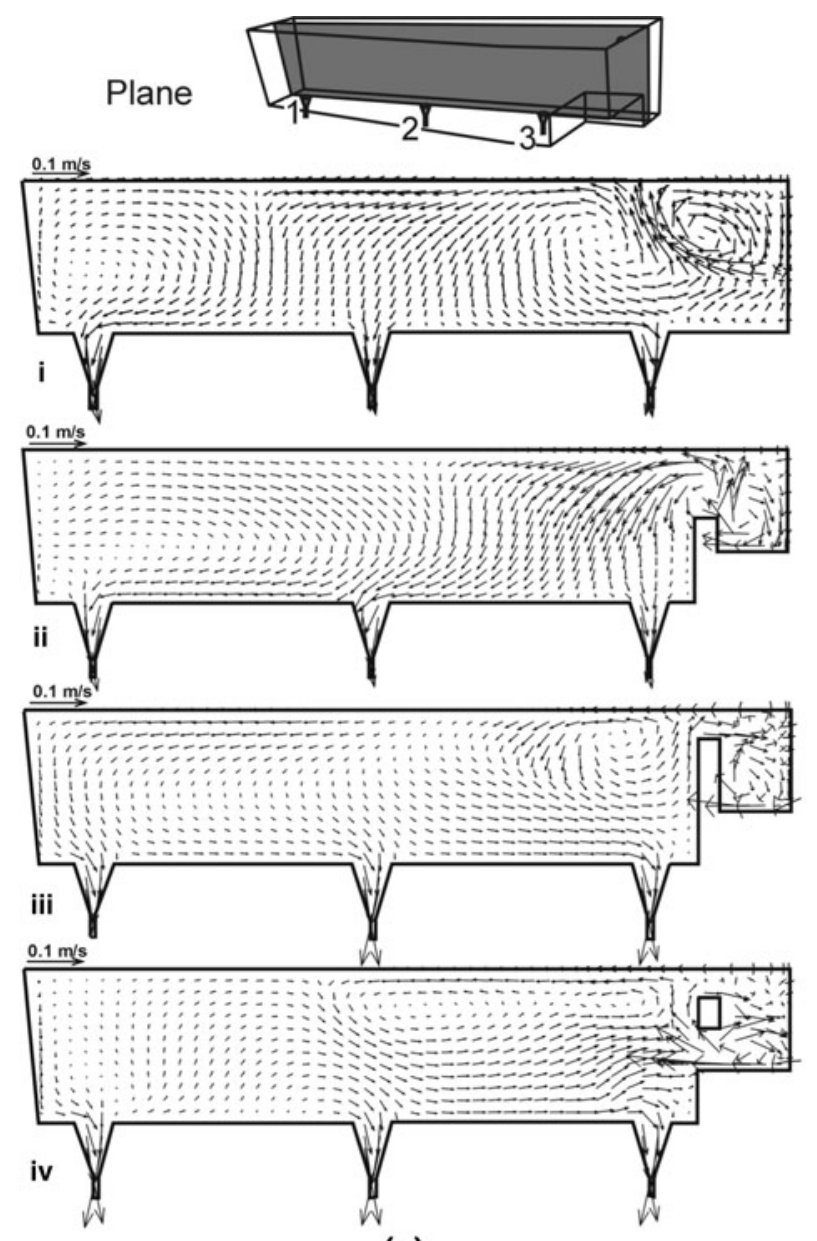

(a)

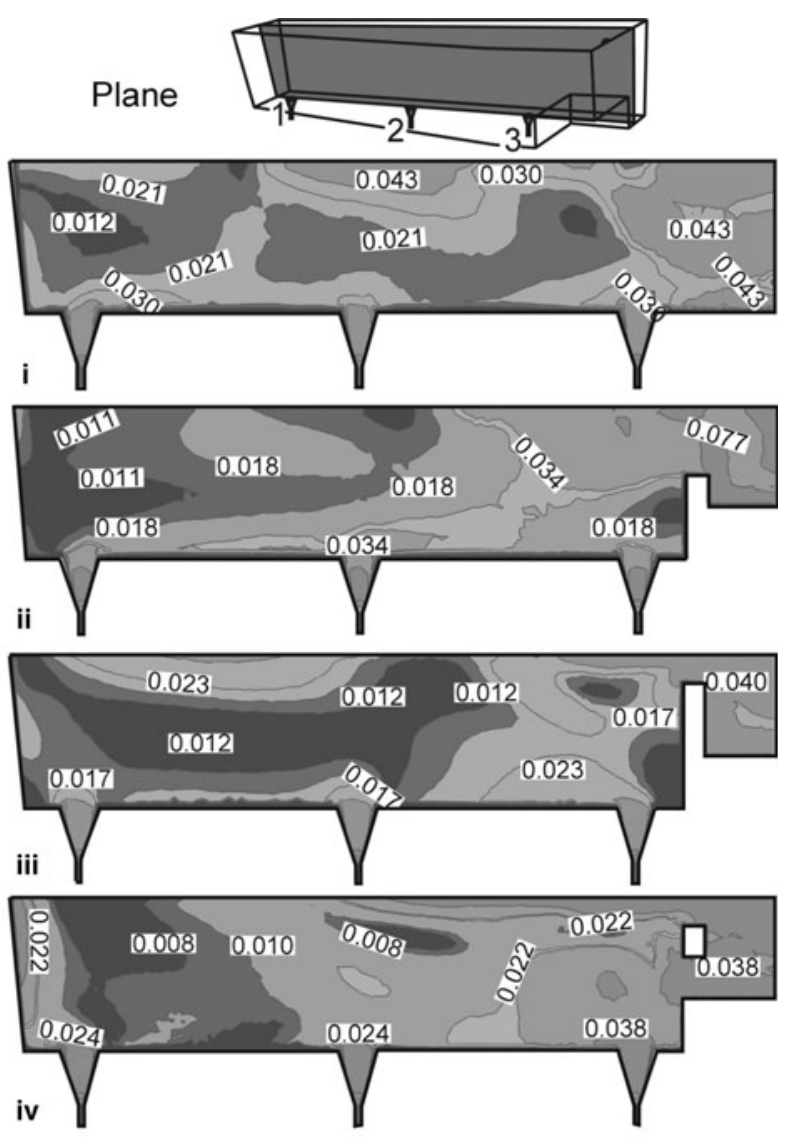

(b)

Fig. 9-(a) Liquid steel velocity vectors: (i) industrial tundish, (ii) Case I, (iii) Case II, and (iv) Case III. (b) Distribution of liquid steel velocity (m/s): (i) industrial tundish, (ii) Case I, (iii) Case II, (iv) Case III. 

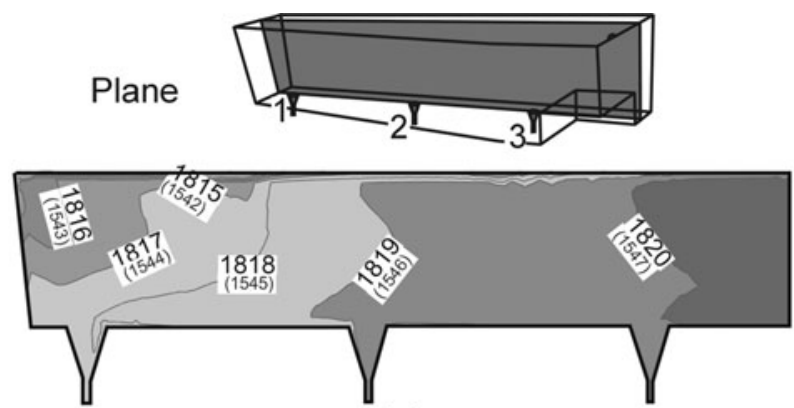

(a)

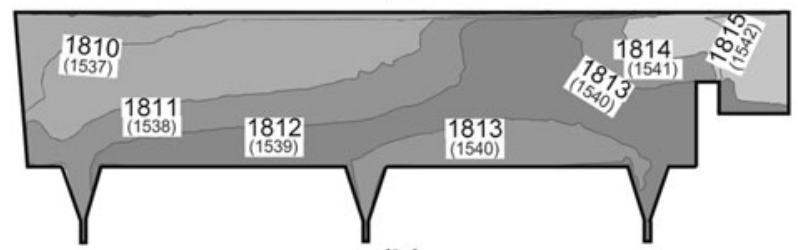

(b)

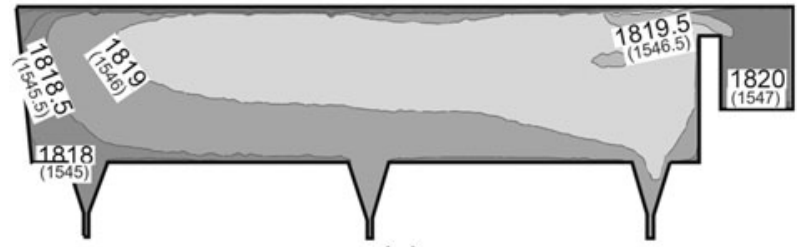

(c)

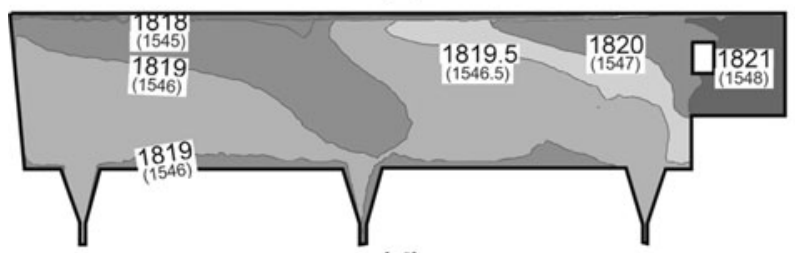

(d)

Fig. 10 -Distribution of liquid steel temperature $\mathrm{K}\left({ }^{\circ} \mathrm{C}\right)$ : $(a)$ industrial tundish, (b) Case I, (c) Case II, and (d) Case III.

values differ slightly, which in turn provides stability of the continuous casting process.

\section{The F curve}

Additionally, an estimation of the liquid steel behavior in the tundish, which gives the solution of the mathematical model, is possible by tracking the tracer concentration distribution in the fluid - a kind of a marker in the liquid steel. Figure 11 shows the projected image of the dimensionless tracer concentration changes after 100 seconds of casting.

The distribution of tracer concentration in liquid steel at chosen planes showed that the tracer in the steel travels mostly through forced convection, resulting from the flow of steel in the tundish. For all analyzed tundish working space modifications, dimensionless tracer dispersion after 100 seconds reached the level of 0.3 in most tundish areas. The tracer homogeneity at the following nozzles can also be observed.

Three-dimensional distributions of steel velocity, as well as the fields of temperature and tracer concentrations in the tundish working space, provide a source of good knowledge about steel casting conditions.

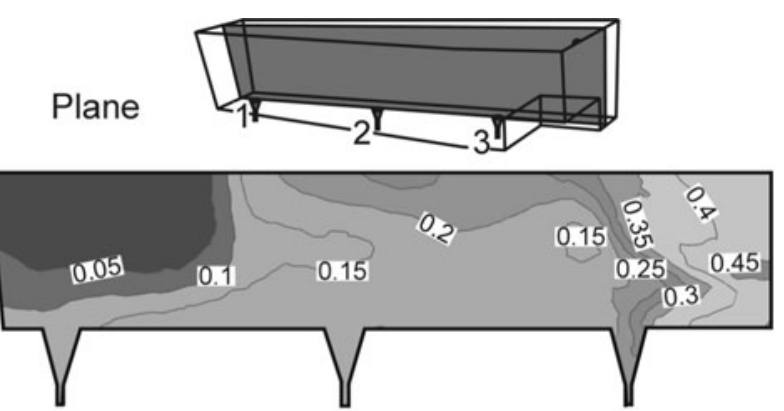

(a)

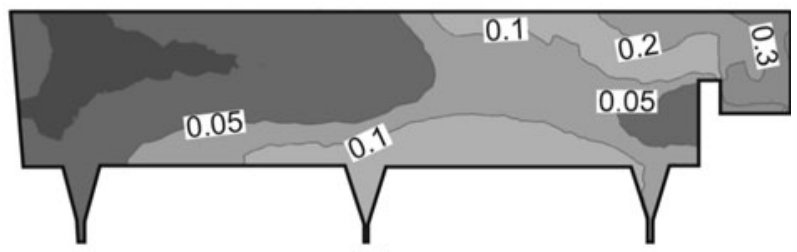

(b)

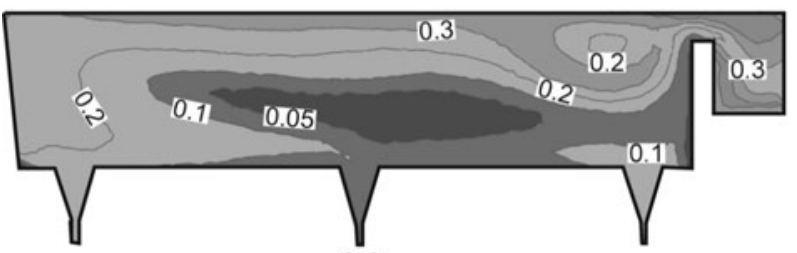

(c)

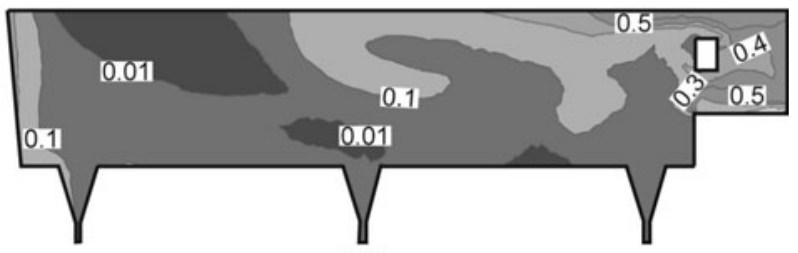

(d)

Fig. 11-Distribution of tracer concentration after $100 \mathrm{~s}$ : $(a)$ industrial tundish, (b) Case I, (c) Case II, and (d) Case III.

However, these characteristics do not enable one to judge directly whether the identified condition of steel flows in the tundish is appropriate for, e.g., the processes of mixing (in sequence casting of different steel grades) or nonmetallic inclusion removal.

Detailed answers to these questions were obtained using macroscopic RTD characteristics (E and F curves) that belong to the canon of studies on flow reactors. ${ }^{[32]}$

To plot the F curves, variations in tracer concentration of the steel flowing out were monitored continuously on the tundish nozzle cross sections. To compare these curves for the plants studied, the results are given in a dimensionless form.

The dimensionless tracer concentration values were obtained directly from a simulation, whereas their corresponding dimensionless time magnitudes were calculated from the relationship provided in Reference 33. The outcome of this transformation is dimensionless mixing time characteristics (the F curve) for the tundish modifications under consideration. They are presented in Figures 12 through 15. 
Noticeable differences are found between the curves describing steel mixing times for individual nozzles in the tundish equipment variants under analysis because of the flow pattern formed in the vicinity of the nozzles, and it is related to the changes in the tundish working space, which cause a disturbance of the steel flow.

The characteristics discussed (Figures 12 through 15) indicate that in all considered plants (which is the reference tundish and the proposed tundish variants), a well-mixed volume flow is predominant. By undertaking the evaluation of the tundish operation in the hydrodynamic meaning, it can be found that the work of the

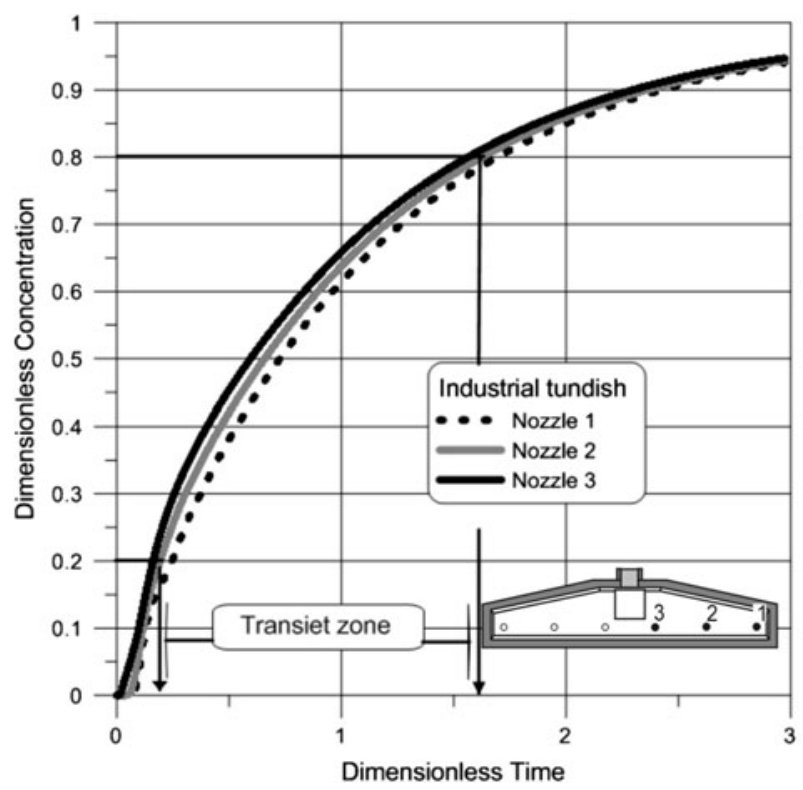

Fig. 12-Dimensionless mixing time characteristic (the F curve) the original industrial tundish.

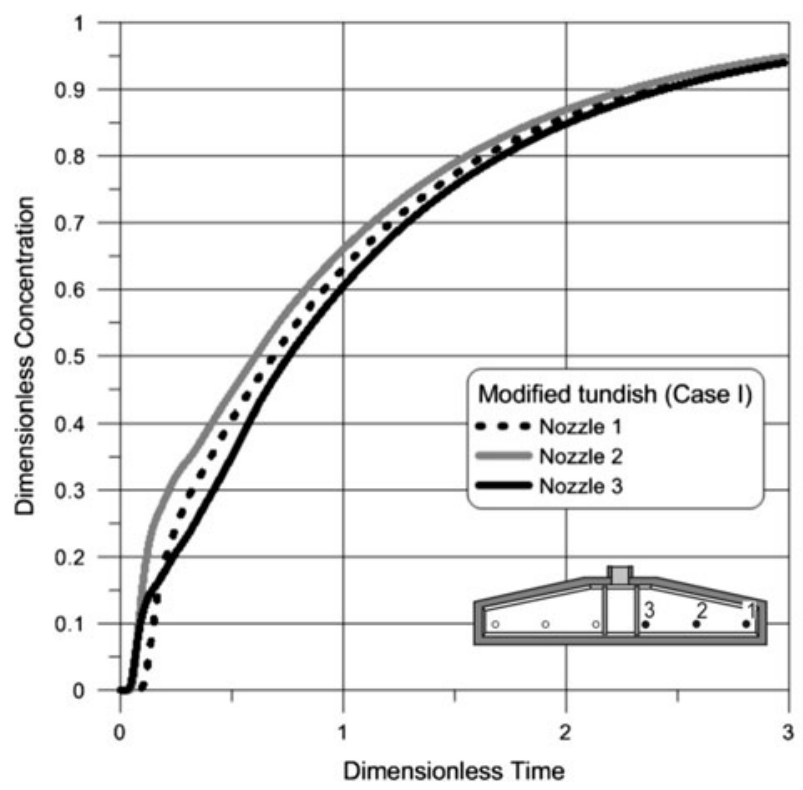

Fig. 13-Dimensionless mixing time characteristic (the F curve) Case I. tundishes is essentially correct and allows to the sequence casting of different steel grades. But this is only a qualitative assessment. The answer concerning the quantitative assessment will be provided by determining the extent of the transient zone.

Oscillations observed for nozzle 2 (the F-curve at Figure 15 and the E-curve in Figure 19) can be the result of two opposite oscillated vortexes in close area of nozzle 2, which is responsible for the wave introducing of the tracer.

Assuming that the value 0 on the axis of ordinates of the presented curves (Figures 12 through15) represents

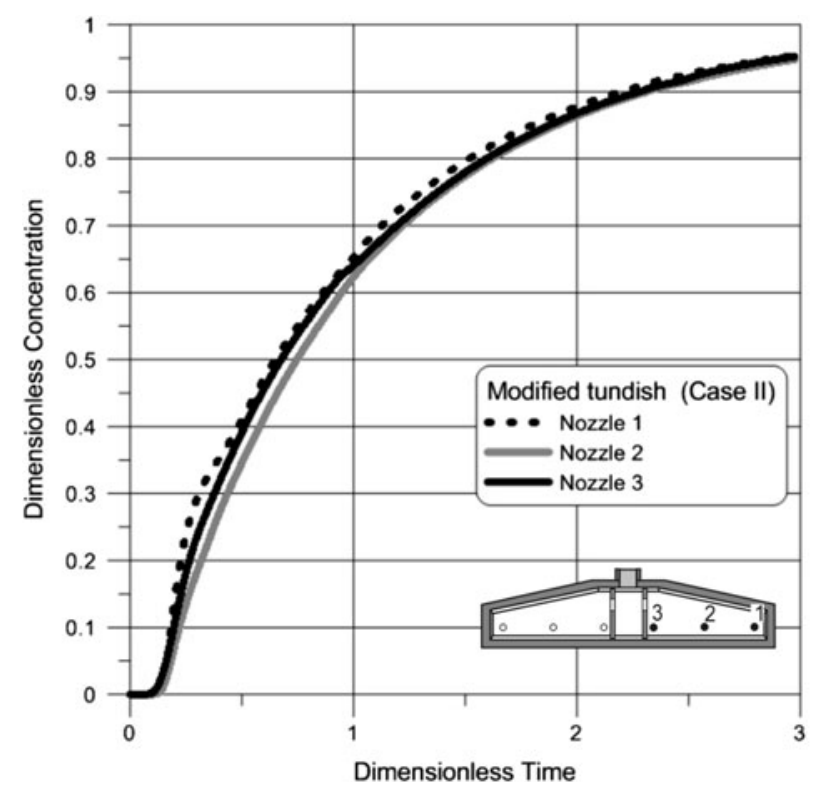

Fig. 14-Dimensionless mixing time characteristic (the F curve)Case II.

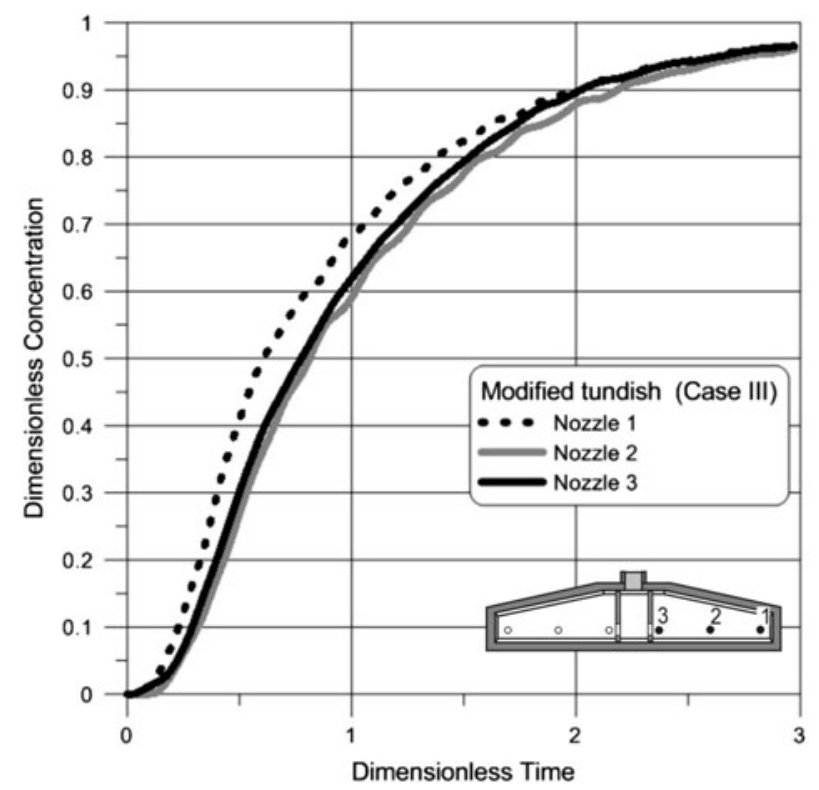

Fig. 15-Dimensionless mixing time characteristic (the F curve)Case III. 
the current grade of steel being cast, one can determine the size of the transient zone extent (this value is assumed for the dimensionless concentration in range of 0.2 to 0.8 ).

For the determination of the transient zone extent, the detailed mixing time characteristics for individual nozzles of the tundish variants under examination, as shown in Figures 12 through 15, were used. The determined transient zone extent values for particular characteristics corresponding to all the nozzles are given in Table IV.

The mean value of the individual tundish nozzles (Table IV) was recognized as the reliable evaluation of the transient zone extent for the entire plant. The smallest value of the mean transient zone extent is 542 seconds for tundish variant (case III). This time decreased significantly in relation to the original industrial plant. In the case of the proposed tundish variant (case I), the tundish with baffles, only a slight reduction of the transient zone extent was observed. A clear reduction of the transient zone occurred for the proposed tundish equipment variants, in which flow-control devices in the form of notched baffles were provided.

If the transient zone extent for a given tundish is known, then it is easily possible to determine the mass of the cast steel deviating with its chemical composition and material properties from the specifications applicable to that steel grade. The calculated steel masses for individual plants are shown in the last column of Table IV.

Comparing the obtained masses, it can be found that in the tundishes with the proposed working space outfit, the cast steel mass corresponding to the transient zone range has decreased, which has also decreased the mass of the concast billet with uncertain chemical composition. These results provide clear evidence that the industrial tundish is not an optimal plant for the casting process in terms of the transient zone during sequence casting of different steel grades.

\section{The E curve}

The F-type curves discussed previously, even though they serve their purpose for the evaluation of flow, are sensitive for assessing the flows that occur in the tundishes. For the evaluation of flow in tundishes, residence time distribution characteristics are the best. A detailed justification for using the characteristics of this type can be found in the literature. ${ }^{[34]}$ By examining these curves, the macroscopic pattern of flow in a plant under study can be evaluated. As mentioned, three regions of liquid steel flow are distinguished in the tundish, namely a dispersed plug flow zone, in which the liquid steel flows in a stable manner; a well-mixed volume flow zone, where the flow is turbulent and a complete mixing of the steel occurs; and the dead volume (stagnant) flow zone, in which the movement of the steel bath is negligible.

To gather the data that are necessary for plotting E-type curves, numerical simulations were performed. At the shroud, a boundary condition representing a pulse change in tracer concentration was used. The variations in traces concentration were recorded continuously for each tundish nozzle with a sampling step of 0.5 seconds for a duration of 3500 seconds.

For objectivity, before a comparison, the results have been transformed into a dimensionless form. To determine the dimensionless tracer concentrations, the following relationship was used:

$$
C_{\mathrm{b}}=C_{i, \mathrm{sym}} / C_{\mathrm{av}}
$$

The mean tracer concentration in perfect mixing conditions is defined as follows:

$$
C_{\mathrm{av}}=m_{\mathrm{t}} / V \cdot \rho_{\mathrm{s}}
$$

An important parameter of the tundish is the resident time of the fluid in the tundish. The real time spent by the fluid element in the tundish can be delivered experimentally by measuring the tracer concentration and solving the following equation ${ }^{[33]}$ :

$$
t_{\mathrm{av}}=\int_{0}^{\infty} C t d t / \int_{0}^{\infty} C d t \cong \frac{\sum C_{i, \mathrm{sym}} t_{i} \Delta t_{i}}{\sum C_{i, \mathrm{sym}} \Delta t_{i}}
$$

Figures 16 through 19 show dimensionless concentration characteristics for the analyzed tundish variants. A theoretical characteristic describing an ideal mixing reactor $^{[32]}$ is plotted additionally in the figures. The ideal mixing curve is calculated for a case where complete mixing occurs and is defined in Reference 32. For ideal mixing, the value of the dimensionless concentration at the moment of dimensionless time $=0$ equals one and decreases with time.

When assessing the behavior of flow in an actual reactor (tundish) in terms of its suitability for refining purposes, usually we refer to idealized reactors or those characterized by solely one type of flow. Such an assessment is largely qualitative only, but it gives the possibility to obtain information about the hydrodynamic conditions prevailing in the facility under examination in the most expeditious manner.

Even after a brief examination of the figures, it can be found that the residence time curves for respective

Table IV. Transient Zone Results

\begin{tabular}{lccccc}
\hline & \multicolumn{4}{c}{ Transient Zone (S) } & Casted Steel \\
\cline { 2 - 5 } Tundish Configuration & Nozzle 1 & Nozzle 2 & Nozzle 3 & Average & Mass (Ton) \\
\hline Current configuration & 730 & 724 & 707 & 720 & 21.7 \\
Modified (case I) & 708 & 711 & 730 & 637 & 16 \\
Modified (case II) & 629 & 635 & 548 & 542 & 16.2 \\
Modified (case III) & 515 & 562 & 549 & \\
\hline
\end{tabular}




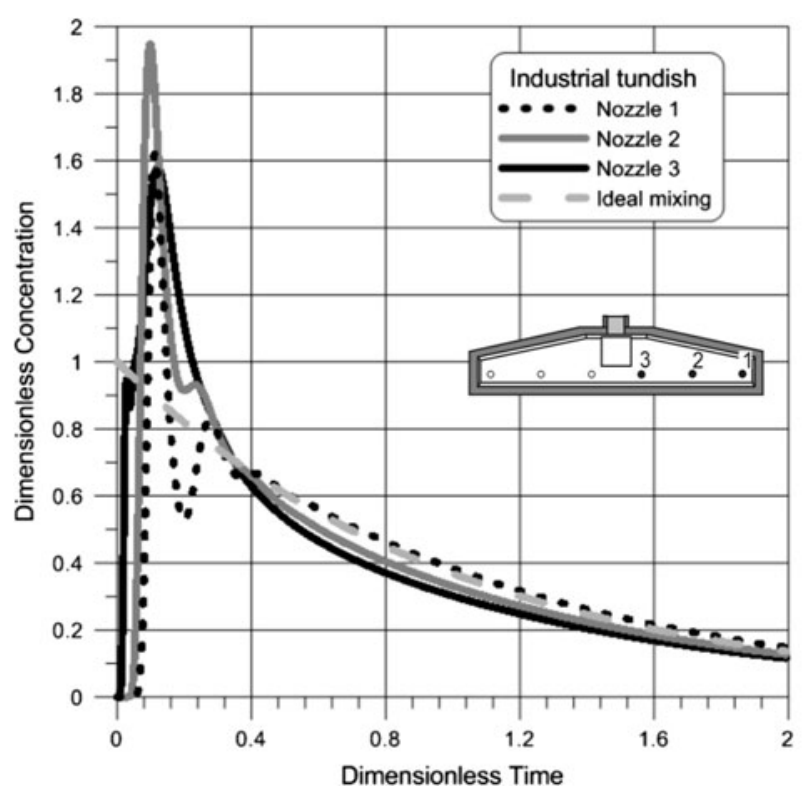

Fig. 16-Dimensionless residence time characteristic (the E curve) the industrial plant.

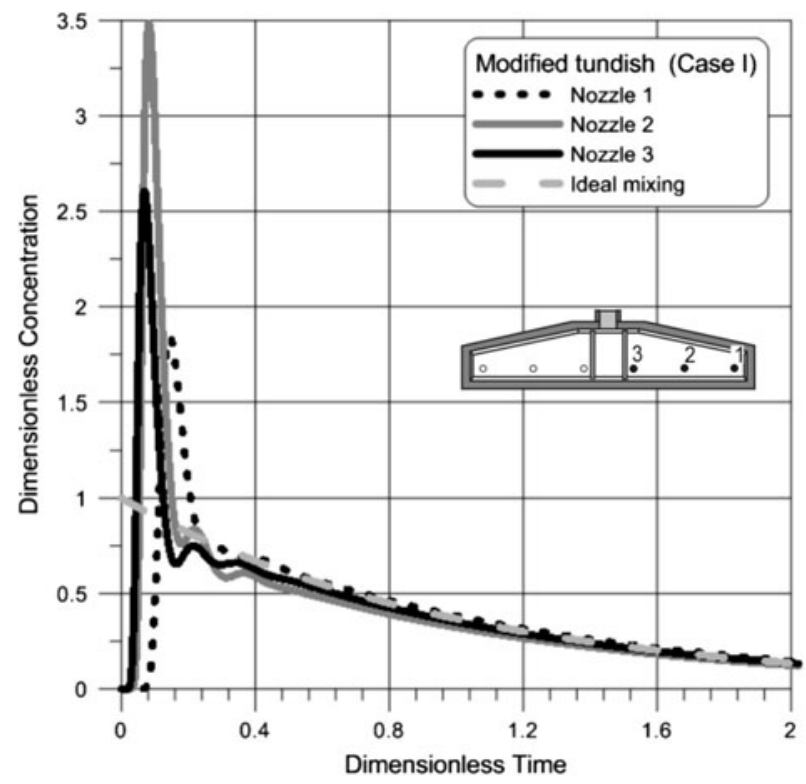

Fig. 17-Dimensionless residence time characteristic (the E curve) numerically predicted (Case I).

variants differ from themselves and deviate from the theoretical ideal mixing curve, especially in their initial phase, which is from the moment of dimensionless time equals 0 up to the dimensionless time equals 0.4 . Significant differences are observed between these characteristics for individual nozzles of the analyzed tundish variants within the same time interval. Beyond this interval, however, the differences between individual nozzles are negligible.

It is also noticed (Figures 16 and 17) that a distinct share of bypass (short circuit) flow in nozzles is visible, which is higher for nozzle number 2 as for the other

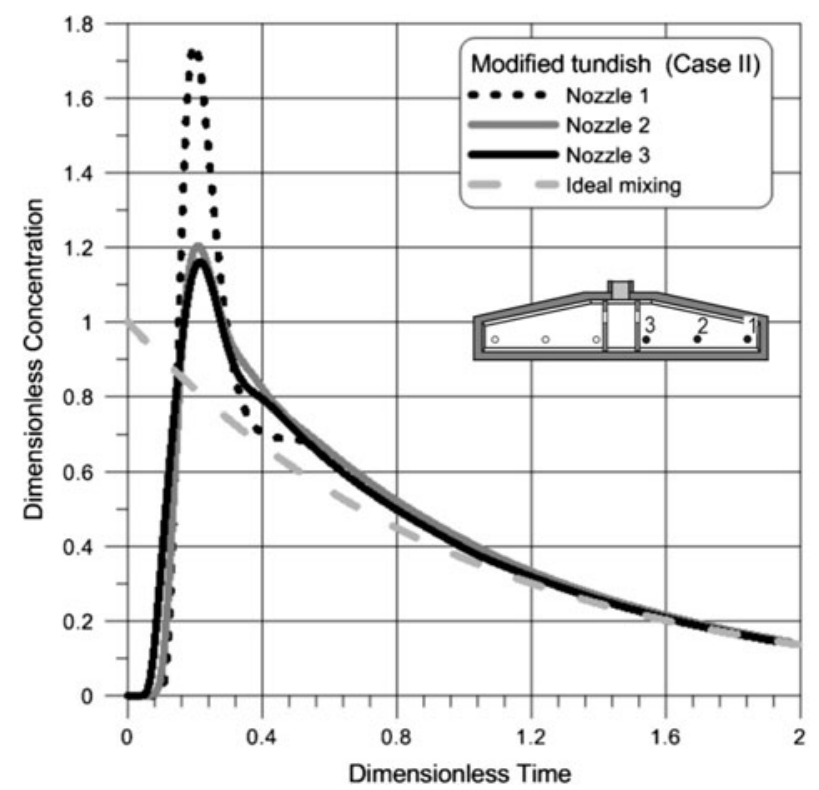

Fig. 18-Dimensionless residence time characteristic (the E curve)numerically predicted (Case II).

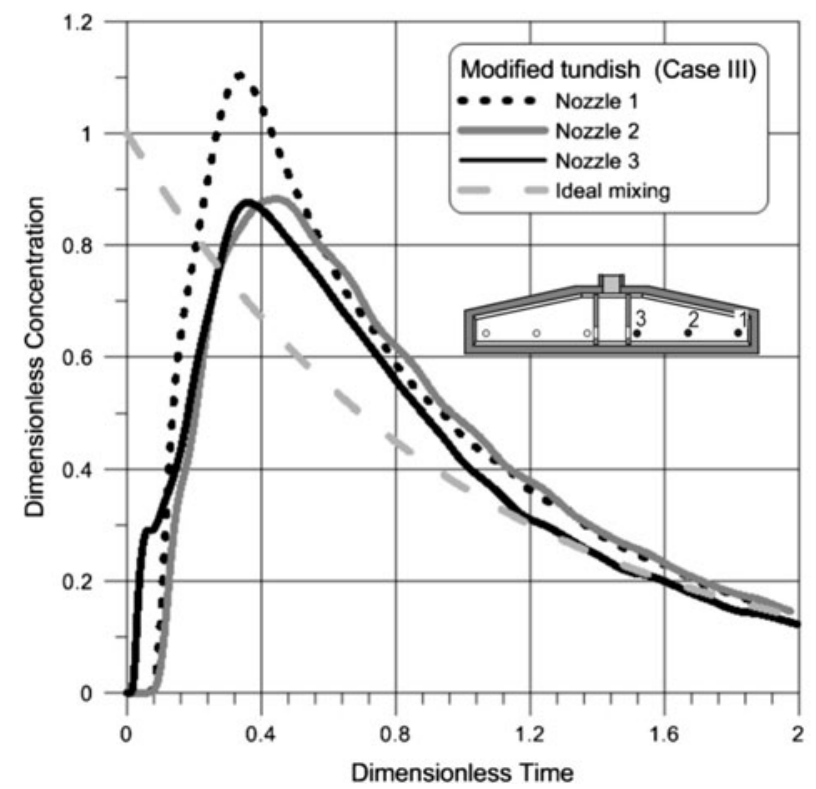

Fig. 19-Dimensionless residence time characteristic (the E curve)numerically predicted (Case III).

nozzles. The appearance of the bypass flow means an adverse feature of the tundish, as it is unfavorable to the flotation of the nonmetallic inclusions (because of short residence time), which affect the quality of the concasts. In the tundish variants with proposed equipment in the form of notched baffles, the bypass flow disappeared, which is observed clearly in Figures 18 and 19 (changed in the shape of the curve for nozzle number 2). For the variant with baffles (Figure 4), in contrast, an impairment of the steel flow conditions is observed. It is also worthy of noting that the installed baffles essentially eliminate the danger of the short-circuit flow of steel for 
Table V. Residence Time Distribution Parameters and Volume Fraction of Flow in the Six-Strand Tundish

\begin{tabular}{|c|c|c|c|c|}
\hline \multirow[b]{2}{*}{ Nozzle Number } & \multirow[b]{2}{*}{$\begin{array}{l}\text { Mean Residence } \\
\text { Time }\left(t_{\text {av }}\right)(\mathrm{s})\end{array}$} & \multicolumn{3}{|c|}{ Volume Fraction (pct) } \\
\hline & & $\begin{array}{l}\text { Dead Volume } \\
\text { Fraction }\left(V_{\mathrm{d}}\right)\end{array}$ & $\begin{array}{c}\text { Dispersed Plug } \\
\text { Volume Fraction }\left(V_{\mathrm{dp}}\right)\end{array}$ & $\begin{array}{c}\text { Well-Mixed } \\
\text { Volume Fraction }\left(V_{\mathrm{m}}\right)\end{array}$ \\
\hline \multicolumn{5}{|c|}{ Tundish-Current configuration } \\
\hline 1 & 546 & 38.4 & 8.8 & 52.8 \\
\hline 2 & 484 & 44.4 & 7.0 & 48.6 \\
\hline 3 & 451 & 48.1 & 6.6 & 45.3 \\
\hline \multicolumn{5}{|c|}{ Tundish-Modified (case I) } \\
\hline 1 & 529 & 37.6 & 11.3 & 51.1 \\
\hline 2 & 543 & 46.0 & 6.3 & 47.7 \\
\hline 3 & 487 & 42.6 & 4.9 & 52.5 \\
\hline \multicolumn{5}{|c|}{ Tundish-Modified (case II) } \\
\hline 1 & 482 & 35.2 & 15.0 & 49.8 \\
\hline 2 & 499 & 33.6 & 13.6 & 52.8 \\
\hline 3 & 490 & 35.9 & 15.3 & 48.8 \\
\hline \multicolumn{5}{|c|}{ Tundish-Modified (case III) } \\
\hline 1 & 482 & 27.3 & 21.0 & 51.7 \\
\hline 2 & 516 & 27.9 & 26.0 & 46.1 \\
\hline 3 & 480 & 36.1 & 18.0 & 45.9 \\
\hline
\end{tabular}

all the nozzles. This result is favorable, as this phenomenon is adverse to nonmetallic inclusion flotation.

Based on a qualitative analysis of the curves, it can be stated that the type of flow control device has a significant effect on the change of the steel flow behavior. Also, the previously noted advantages of equipping the tundish working space with notched baffles and their role in creating optimal steel casting conditions are confirmed.

The developed liquid steel residence time curves suggest the possibility of determining precisely the shares of the particular flows. To determine these shares and to calculate the mean residence time for the analyzed tundish variants, additional computations according to the formulas provided in References 22 and 32 were performed. The calculated shares of flows for specific nozzles are summarized in Table V.

The shares of flows in the analyzed tundish variants, shown in Table $\mathrm{V}$, differ significantly for respective nozzles. For nozzle 3, which is most exposed to adverse casting conditions, a small share of dispersed plug flow and a large share of dead volume flow are identified for all the tundish variants.

The most unfavorable proportion of flow shares can be found for the reference tundish case and for tundish variant (case I), which indicates the appearance of a short-circuit flow between the gate and nozzle 3 of the tundish. This result is confirmed by the residence time characteristics for these tundishes. In the remaining tundish variants with notched baffles, the share of the plug flow increases and the share of dead volume flow decreases. Practically, no bypass flow occurs. For nozzles 1 and 2 in the tundish equipment variants, the proportions of particular flow shares have improved compared with the reference tundish.

The optimal working space of a tundish should be characterized by a relatively small difference between the mean steel residence times for the respective nozzles. ${ }^{[33,35,36]}$ The data contained in Table $\mathrm{V}$ confirmed the smallest residence time differences between the nozzles in the notched baffles tundish variants. It can, therefore, be assumed that each tundish nozzle has the same chance of the spontaneous refining processes to be accomplished in the steel being cast, which will assure the almost identical metallurgical purity of all cast concasts.

The data summarized in Table $\mathrm{V}$ indicate that the flow-control devices employed in the working space of the plant influence significantly the magnitudes of the flows shares on individual nozzles and, thus, within the entire tundish volume. However, the implementation of the tundish working space equipment has only a slight effect on the share of well-mixed volume flow, which averages approximately 50 pct of all examined plants. A large, well-mixed volume flow share in the investigated tundish variants is confirmed also by the F-type curves.

In closing, it can be stated that both the tundish variants with mounted notched baffles are characterized by a smaller extent of the transient zone; therefore, both improve the conditions of operation of the actual tundish. However, if the shares of particular flows are additionally taken into account, it can be found that the optimal tundish operation conditions will be achieved for case III.

\section{Additional Plant Measurements}

In view of the previous findings, an additional industrial experiment was carried out, for which the aim was to verify the previous simulation study results. The tests were based on gathering data from the rebuilt industrial tundish (according to case III) and then developing a mixing characteristic (Figure 20) that gives the possibility to interpret the transient zone size.

Even a brief examination of this figure allows one to notice an agreement between the dimensionless tracer concentrations coming from experimental test and numerical simulation. Such an agreement warrants 


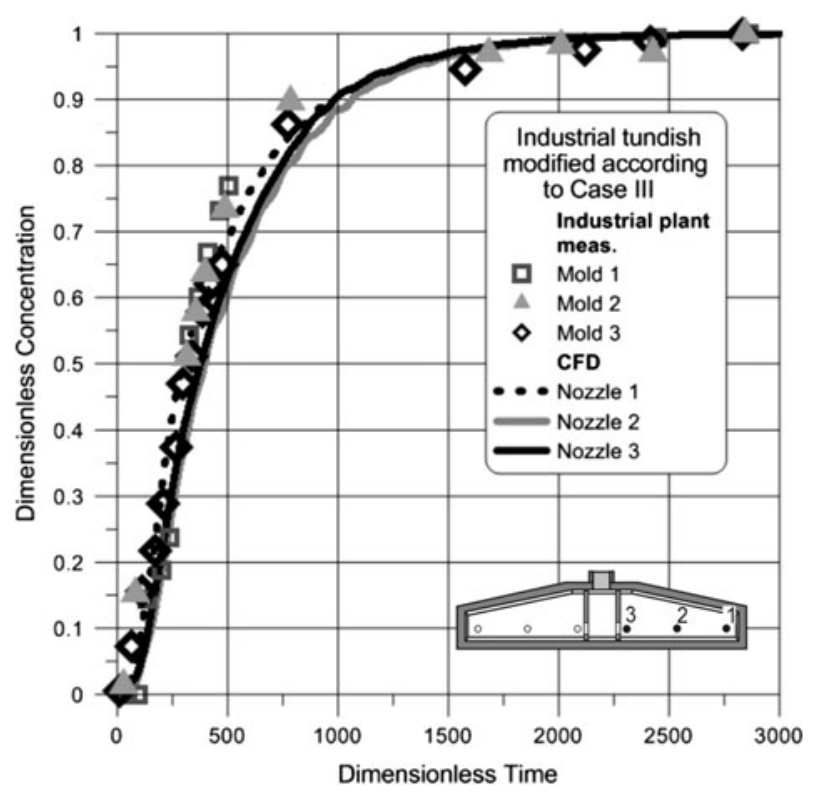

Fig. 20 - Cu concentration in steel bath-measured experimentally and predicted numerically for the modified industrial tundish configuration.

Table VI. Transient Zone Extent Measured and Calculated for the Industrial Tundish (Case III)

\begin{tabular}{lcccc}
\hline & \multicolumn{4}{c}{ Transient Zone (s) } \\
\cline { 2 - 5 } Modified According & $\begin{array}{c}\text { Nozzle/ } \\
\text { Mold }\end{array}$ & $\begin{array}{c}\text { Nozzle/ } \\
\text { Mold }\end{array}$ & $\begin{array}{c}\text { Nozzle/ } \\
\text { Mold }\end{array}$ \\
Industrial Tundish & 1 & 2 & 3 & Average \\
\hline Experiment & 500 & 530 & 515 & 515 \\
CFD & 515 & 562 & 549 & 542 \\
\hline
\end{tabular}

searching for information about the extent of the transient zone in sequence casting. The values of a particular transient zone extent were determined for three nozzles following the procedures discussed previously. From the gathered transient zone extent data, the mean value as the reliable measure of the transient zone of the entire plant was determined (Table VI).

The existing differences in the transient zone extent between the data originated from the experiment and from the numerical computation are relatively small, as this deviation does not exceed 7 pct both for the nozzles and for the mean value. It should be stressed that the trend in changes for individual nozzles has been retained. Therefore, it should be expected that the modernized tundish will assure good metallurgical quality of concasts and will stabilize the continuous casting process.

\section{CONCLUDING REMARKS}

The analysis of the presented results of both the industrial experiment and numerical simulations allows the following conclusions to be drawn:
1. The flow analysis reveals definitely unfavorable proportions of particular flow shares and a particularly small share of dispersed plug flow to prevail in the industrial tundish.

2. The proposed tundish working space equipment variants bring about a decrease of the liquid steel residence time, which develops the casting conditions positively.

3. The determined transient zone extent parameter for the examined tundishes varies in a specific manner, depending on the type of tundish equipment. Equipping the tundish working space with CFD resulted in a decrease of the transient zone extent. The tundish according to case III with the lowest value of this parameter can be regarded as optimal.

4. The numerically determined volumetric shares of steel flow in the proposed variants of tundish equipment indicate a growing share of dispersed plug flow and a decreasing share of the dead volume flow with a practically unchanging share of well-mixed volume flow. The most advantageous flow share proportions are noted for the tundish (case III).

Conclusions given above confirm the need for equipping the working space of the industrial tundish with flow control devices, such as the notched baffles (Case III).

\section{OPEN ACCESS}

This article is distributed under the terms of the Creative Commons Attribution License which permits any use, distribution, and reproduction in any medium, provided the original author(s) and the source are credited.

\section{NOMENCLATURE}

C concentration of the tracer

$C_{\mathrm{av}} \quad$ average concentration of the tracer in case of ideal mixing

$C_{\mathrm{b}} \quad$ dimensionless concentration

$C_{i, \text { sym }}$ tracer concentration calculated numerically in the specified time

$C_{\mathrm{o}} \quad$ initial concentration of the tracer

$C_{\mathrm{t}} \quad$ tracer concentration at time $t$

$C_{\infty} \quad$ final concentration of the tracer

$D_{\text {eff }} \quad$ effective diffusion coefficient

$D_{\mathrm{m}} \quad$ molecular diffusion coefficient

$D_{\mathrm{t}} \quad$ turbulent diffusion coefficient

$g_{i} \quad$ gravitational acceleration

$k \quad$ turbulence kinetic energy

$k_{\text {eff }} \quad$ effective thermal conductivity

$m_{\mathrm{t}} \quad$ mass of the tracer

$\mathrm{Q}_{v} \quad$ volumetric flow rate

$t \quad$ time

$t_{\mathrm{av}} \quad$ mean residence time

$t_{i} \quad$ specified time

$u \quad$ velocity 
$u_{i, j} \quad$ velocity components

$V \quad$ volume of liquid in the tundish

$V_{\mathrm{d}} \quad$ dead volume friction

$V_{\mathrm{dp}} \quad$ dispersed plug volume friction

$V_{\mathrm{m}} \quad$ well-mixed flow volume friction

$\varepsilon \quad$ dissipation rate of the turbulent kinetic energy

$\mu \quad$ dynamic coefficient of viscosity

$\mu_{\text {eff }} \quad$ effective coefficient of viscosity

$\mu_{\mathrm{t}} \quad$ dynamic coefficient of turbulent viscosity

$\rho \quad$ specific density

$\rho_{\mathrm{s}} \quad$ liquid steel density

\section{REFERENCES}

1. Y. He and Y. Sahai: Metall. Trans. B, 1987, vol. 18B, pp. 81-92.

2. R.K. Singh, A. Paul, and A.K. Ray: Scand. J. Metall., 2003, vol. 32 , pp. 137-46.

3. R.D. Morales, J.J. Barreto, S. Lopez-Ramirez, J. Palafox-Ramos, and D. Zacharias: Metall. Mater. Trans. B, 2000, vol. 31B, pp. $1505-15$.

4. L.G. Demedices, R.D. Morales, S. Lopez-Ramirez, J.J. BarretoSandowal, and J. Palafox-Ramos: Steel Res. Int., 2001, vol. 72, pp. $346-52$.

5. D. Mazumdar, G. Yamanoglu, and I.L. Guthrie: Steel Res. Int., 1997, vol. 68, pp. 293-300.

6. R. Schwarze, F. Obermeier, J. Hantusch, A. Franke, and D. Janke: Steel Res. Int., 2001, vol. 72, pp. 215-20.

7. K. Sahai and Y. Mizukami: ISIJ Int., 2000, vol. 40, pp. 40-47.

8. F. Shen, J.M. Khodadadi, S. Pine, and X. Lan: Metall. Mater. Trans. B, 1994, vol. 25B, pp. 669-80.

9. C.E. Grip: ISIJ Int., 1998, vol. 3, pp. 704-13.

10. M. Warzecha, T. Merder, H. Pfeifer, and J. Pieprzyca: Steel Res. Int., 2010, vol. 81, pp. 987-93.

11. T. Merder, J. Pieprzyca, and M. Warzecha: Metalurgija, 2009, vol. 3, pp. 143-46.

12. K. Janiszewski and Z. Kudliński: Steel Res. Int., 2006, vol. 3, pp. $169-76$.

13. R.D. Morales, S. Lopez-Ramirez, J.J. Barreto, and R.J. Palafox: 17th Proc. Technology Conf. Proc, Orlando, FL, 2000, pp. 955-89.

14. S. Chakraborty and Y. Sahai: Metall. Trans. B, 1992, vol. 23B, pp. 153-67.

15. J. Palafox-Ramos, J.J. Barreto, S. Lopez-Ramirez, and R.D. Morales: Ironmaking Steelmaking, 2001, vol. 28, pp. 101-09.
16. S. Lopez-Ramirez, J.J. Barreto, J. Palafox-Ramos, R.D. Morales, and D. Zacharias: Metall. Mater. Trans. B, 2001, vol. 32B, pp. 615-27.

17. A. Zamora, R.D. Morales, M. Diaz-Cruz, J. Palafox-Ramos, and J.J. Barreto-Sandoval: Metall. Mater. Trans. B, 2004, vol. 35B, pp. $247-57$.

18. R.D. Morales, A. Ramos-Banderas, and R. Sanchez-Perez: AISTech Proc., Nashville, TN, 2004, vol. 2, pp. 867-77.

19. H.J. Odenthal, H. Pfeifer, and M. Klaas: Steel Res. Int., 2000, vol. 71 , pp. $210-20$.

20. A. Aguiler-Corona, R.D. Moreles, M. Diaz-Cruz, J. Palafox-Ramos, and H. Rodriguez-Hernandez: Steel Res. Int., 2002, vol. 73, pp. 43844.

21. T. Merder, M. Warzecha, K. Mierzwa, I. Staniewski, A. Cwudziński, and D. Mendak: 5th Scient. Conf. New Technologies and Achievements in Metallurgy and Materials Engineering, 2007, Czestochowa, Poland, pp. 383-86.

22. M.L. Lowry and Y. Sahai: Ironmaking Steelmaking, 1992, vol. 19 , pp. 81-86.

23. M. Clark, T. Wagner, and A. Trousset: IOM Annual Ceramics Convention, 2002, pp. 14-17.

24. H.J. Odenthal, R. Bölling, and H. Pfeifer: Steel Res. Int., 2003, vol. 74 , pp. $44-55$.

25. T. Merder, A. Bogusławski, and J. Jowsa: Arch. Metall. Mater., 2005, vol. 50 , pp. $933-53$

26. T. Merder: Ph.D. Dissertation, TU Czestochowa, Poland, 2007.

27. J.F. Wendt: Computational Fluid Dynamics, Springer-Verlag, Berlin, Germany, 1996, pp. 77-86.

28. T. Merder, A. Bogusławski, and M. Warzecha: Metalurgija, 2007 vol. 46, pp. 245-49.

29. B.E. Launder and D.B. Spalding: Lectures in Mathematical Models of Turbulence, Academic Press, London, U.K, 1972, p. 169.

30. FLUENT: User's Guide, Version 6.0, ANSYS Inc., Canonsburg, PA, 2003.

31. T. Merder: Works Institute for Ferrous Metall., 2008, vol. 6, pp. 25-30.

32. C.Y. Wen and L.T. Fan: Models for Flow Systems and Chemical Reactions, Dekker, New York, NY, 1975, pp. 25-88.

33. J. Szekely and O.J. Illegbussi: The Physical and Mathematical Modeling of Tundish Operations, Springer-Verlag, Berlin, Germany, 1989, pp. 39-43.

34. Y. Sahai and T. Emi: ISIJ Int., 1996, vol. 36, pp. 667-72.

35. S. Lopez-Ramirez, J.J. Barreto, P. Vite-Martinez, J.A. RomeroSerano, and C. Duran-Valencia: Metall. Mater. Trans. B, 2004, vol. 35B, pp. 957-66.

36. A. Tripathi and S.K. Ajmani: ISIJ Int., 2005, vol. 45, pp. 161625. 